\title{
Risk Management Under Changing Economic Conditions
}

\author{
by Robert L. Carter *
}

\section{Introduction}

The development of risk management as an identifiably separate staff management function occurred at a time of buoyant economic growth when most industrial and commercial firms could reasonably expect to grow and prosper, and largely the literature reflects that situation. Today for many firms in Britain and elsewhere growth has been replaced by a struggle for survival necessitating a detailed review and, if possible, the pruning of all costs. Consequently the insurance industry in Britain is now suffering from a loss of business resulting not only from company bankruptcies and factory closures, but also more generally through firms seeking to cut expenditure on insurance.

It might be argued that at a time of economic stringency a firm needs more rather than less insurance. For example, it may be advisable to insure against perils with loss potentials which under normal conditions a firm may choose to assume itself, or to reduce the size of the deductibles fixed in more prosperous times (see Gaselee [1981]). Keener price competition between insurers anxious to maintain their own levels of trading activity may serve to reinforce that advice. However, in order to understand what is happening in practice, it is necessary to see risk management decisions in the context of a firm's total operating and financial situation.

\section{Risk management and corporate objectives}

Although the debate regarding the boundaries of risk management as a management function continues unabated, the desirability of a firm integrating its policies for the handling of pure risks within the general framework of its corporate objectives is now well-accepted (Mehr and Forbes [1973], Carter [1974]). However that is easier said than done, as is evidenced by the many economic and behavioural theories of the firm. ${ }^{1}$

* Norwich Union Professor of Insurance Studies, University of Nottingham.

1 For a resume, see for example Hawkins [1973]. 
The validity of the assumption that a firm is a corporate unity pursuing a single goal, and in particular that it sets out to maximise any one measure of performance, whether it be profit, sales revenue, net worth or managerial utility, can be challenged on a number of grounds. Baumol's [1959] and Williamson's [1970] sales revenue and utility maximisation models, for example, are subject to minimum profit constraints. Similarly Drucker [1974] argues that not only does a firm need to earn profits but that need also may impose a limitation on other objectives.

The recognition of profit as either an objective or a constraint acknowledges the interest of shareholders, but they are not the only persons concerned - management, employees, customers and the public at large have an interest too. Consequently behavioural theories do not view firms as having either one major decision-maker or one goal. Firms are complex organizations in which different parts of the organization may have different goals (Cyert and March [1963]) so that in large firms systems have to be introduced to achieve a certain direction of effort and uniformity of purpose. Furthermore, increasingly decision-makers are constrained in the pursuit of their chosen goals by external agencies and forces. For example, failure to comply with pollution, health, or safety regulations may result in the enforced closure of a plant. Also no company can afford to ignore changing conditions in capital markets and, if it wishes to remain an independent entity, what valuation the stock market is placing on its own shares relative to other share prices (see Samuels and Wilkes [1980]).

It is within such a framework that a risk manager must operate. Normally his role involves both the formulation of broad risk handling policies for the approval of top management, and their detailed implementation. During both stages he must pay regard to the objectives which may either be expressed explicitly or be implicit in company policy statements, strategic plans and other documents, though usually there will be some scope for the expression of his own attitudes and goals. For example, various studies dating back to Williams [1966] have revealed that managers tend to be more risk averse in their attitudes towards pure risks than speculative risks. Possibly asymetric patterns of sanctions and rewards may contribute to such attitudes, in that risk managers may receive little reward for reducing risk costs but be disciplined if the policies they advocate result in the firm suffering a large irrecoverable loss or a greater variability of losses. Consequently both the policies a risk manager may advocate and the way he chooses to implement the policies agreed by his superiors, perhaps within specified budgetary limits, may in some cases display greater risk aversion than would be wholly consistent with the corporate objectives.

\section{The effect of changing conditions on corporate objectives and constraints}

Whatever objective (or set of objectives) a firm's decision-makers' care to pursue, the survival of the firm in the long-run depends upon it earning a level of profit that at least will keep its shareholders satisfied : as Drucker [1974] says "Profit is a condition of survival. It is ... the cost of staying in business ". Moreover, as shareholders take much of their return in the form of capital gains, that is, through increases in the 
market prices of their shares, the directors of the company must be aware of how the policies they pursue will affect its share price (see Samuels and Wilkes [1980]). That price, however, is not determined in a vacuum: it will be affected by all of the influences bearing on the supply and demand for capital, and on the performance of the company relative to others. So the minimum rate of profit a company needs to achieve will change over time. The more it can exceed the minimum required rate, the greater the freedom its decision-makers will have to pursue other objectives.

There are times, however, when the prospect of achieving profits is remote, and then temporarily every effort must be devoted just to keeping the company liquid and the value of its shareholders' investment intact. Drucker [1980] argues that:

"In turbulent times ... a business can survive long periods of low earnings or low revenues if it has adequate cash flow and financial strength. The opposite is not true.

... Liquidity by itself is not an objective. But in turbulent times it becomes a restraint. It becomes a survival need"'. (pp. 13-14).

\section{Risk management responses to changing conditions}

Before examining the ways in which risk managers need to respond to changing conditions, it is proposed to consider the choices they have and the constraints thereon.

As shown in Figure 1, pure risks can be controlled both through measures aimed at avoiding or reducing the probability and/or severity of losses occurring (physical loss controls), and through making provision to finance the losses that do occur (financial loss control). Although the two methods differ fundamentally in their approaches to the management of risk, in neither case can a firm afford to take decisions without regard to the financial consequences.

Figure 1: Ways of controlling risks

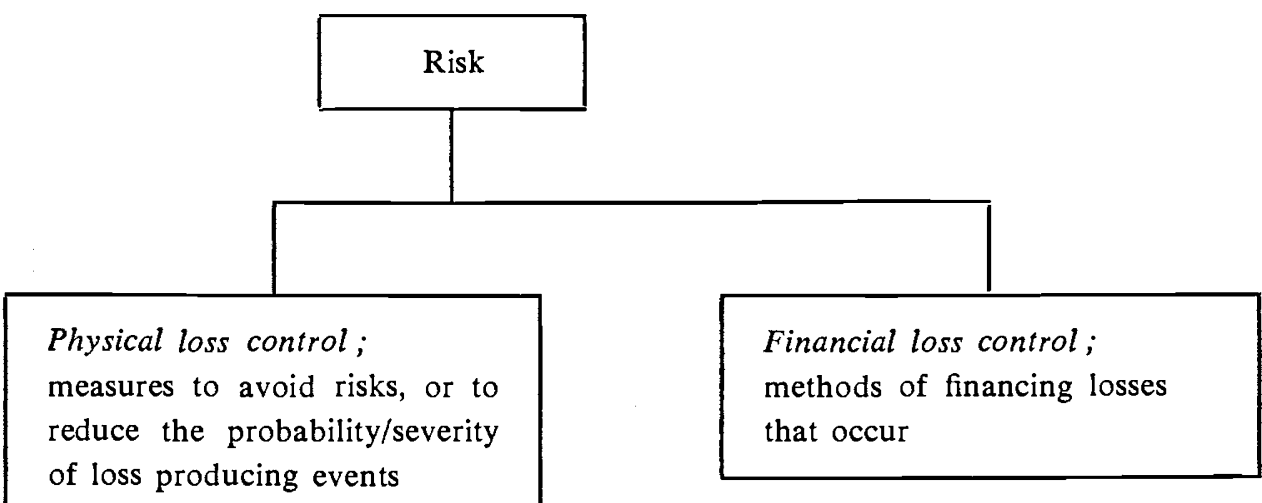


It is well-recognised (see Greene and Serbein [1978], p. 99) that non-economic considerations may enter into physical loss control decisions. The owners and managers of firms may, for example, have a humanitarian approach to matters involving the safety of employees and others which may transcend mere conformity with statutorily imposed safety regulations which themselves may be judged uneconomic. Yet in the final analysis there are limits to how far a firm can disregard the financial implications of any course of action because it must meet its minimum profit constraint and remain liquid.

Greene and Serbein [1978] argue that viewed solely on economic grounds, physical loss control will be pursued so long as benefits exceed costs, and, like Doherty [1976], propose the normal profit maximising rule of equating marginal benefit with marginal cost, with benefit consisting mainly of the expected reduction in future losses and/or savings in insurance premiums. However such a rule suffers from obvious operational difficulties. The flow of costs and benefits over time, and the uncertainty regarding outcomes, can be handled by the same techniques as are used for the evaluation of other types of investment projects, with due account being taken of the timing of the forecast returns, including pay back periods. More fundamentally the rule implies that the firm's objective is to maximise expected profit, but if its decision takers have other goals the saving in expected risk costs would be but one factor. Equally important could be the estimated impact on the size variability of individual and aggregate losses in any one time period, a factor which will interact with financial loss control decisions. So more resources may be expended on eliminating the possibility of suffering very severe losses, even though larger savings in annual loss expectancies may be achieved by tackling events with higher frequencies of occurrence but far smaller individual loss potentials.

Similar considerations apply to methods of financing losses, which can be classified under three headings :

- the charging of losses that occur to current operating costs ;

- ex ante provision, through the purchase of insurance or the setting-up of internal contingency funds ;

- ex post financing through borrowing.

Again both trade-offs between risk handling costs and financial security, and cash-flow effects, need to be considered. Greene and Serbein ([1978], p. 122), for example, claim that the most common objective for self-insuring is to reduce the cost of handling risk and the amount of capital tied-up in reserves. In pursuing such objectives, a risk manager is constrained by the need to keep retained losses within certain limits, which might be laid-down in his own or other departmental budgets. Moreover he must pay regard to the impact of retained losses on the company balance sheet and consequent stock market reactions as reflected in movements in its share price. If a firm could work to an infinitely long planning horizon, then it would never pay to insure because to do so increases annual expected risk costs and thus reduces expected profits, but in the real world liquidity, credit-worthiness and share price considerations focus attention on actual annual risk costs. 
Furthermore, if the company is not to be exposed to a greater risk of liquidity crises, decisions to retain losses without any funding provision must take account too of potential monthly fluctuations in both losses (allowing for the delays between the occurrence and financing of losses) and normal trading cash flows arising out of the firm's operating cycle, including allowance for seasonal factors. Adverse random fluctuations in cash flows, or other unplanned depletions of liquidity, can be handled either by carrying cash reserves or by borrowing. The former is costly in terms of earnings forgone, so that the management of cash and working capital in general involves balancing risk and profitability. The charging of losses to current operating cost adds to that risk, particularly if the loss-producing event interrupts trading activities, so causing a fall in cash inflows. The size and nature of loss producing events likewise may affect a firm's ability to finance losses by borrowing. Credit-worthiness depends upon a firm's capital gearing and even more directly on its ability to service loan capital : additional borrowing after a loss has occurred would add to the financing strain at a time when earnings may be impaired.

It is for such reasons that some risk managers when formulating their risk handling policies, and particularly the use of physical loss controls, pay special attention to those loss producing events which may disrupt earnings and so cash flows. A major liability claim, provided it does not affect sales, can be financed with less strain than a major business interruption loss of equivalent size.

To summarise the above, at all times a risk manager in formulating his company's (pure) risk handling policies needs to pay regard to their effect on :

- expected annual risk costs and so on expected profits ;

- the potential variability of actual annual risk costs and actual profits;

- short-term cash outflows and inflows;

- liquidity ;

- his company's rate of pre-tax earnings to debt financing charges ;

and additional to the factors discussed above :

- the tax treatment of losses, insurance premiums and contributions to internal contingency funds, in view of the impact on post-tax profits and thus the returns on shareholders' funds, and

- the availability and cost of loans.

States of corporate health. It follows from the foregoing that risk handling policies must take account of a company's financial position and be adjusted according to changes therein. There are many ways of testing the financial health of a company 2 , but three of particular relevance in relation to risk handling decisions are those reflecting :

a) liquidity, that is, the ability of a company to meet its liabilities as they fall due for payment, as measured by the quick assets ratio (current assets less stock divided by current liabilities) ;

2 See, for example, Lee [1981]. 
b) profitability, as measured by pre- and post-tax rates of return on (i) long-term and (ii) equity capital employed; and

c) fund raising capacity as measured by the company's capital gearing ratio and, more important, by the ratio of fixed interest charges to gross earnings, which will give an indication of its ability to borrow.

\section{Figure 2: The financial health of companies}

\begin{tabular}{|c|c|c|c|}
\hline Financial Health & & Test result : & \\
\hline & Liquidity & Profitability & $\begin{array}{l}\text { Fund raising } \\
\text { capacity }\end{array}$ \\
\hline Excellent & High & Supra-normal & High \\
\hline Normal & Adequate & Normal & Adequate \\
\hline Sub-normal & Low & Sub-normal & Near zero \\
\hline Terminal & Highly illiquid & Negative & Zero \\
\hline
\end{tabular}

Notes :

Liquidity: relative to degree of liquidity necessary to meet all demands within chosen confidence interval

Profitability: this measures profit potential relative to the rate of return required to satisfy shareholders; it does not necessarily measure actual profits which may reflect $\mathrm{X}$ - inefficiency or other additions to costs.

Using those tests, a company's financial health may be classified broadly as in Figure 2. An adverse position in regard to any one of the tests would indicate a certain degree of financial impairment ; many companies, for example, have failed not through any shortcomings in their profitability but because over-trading has led to illiquidity. Such cases, however, are due to financial mismanagement. When all tests are adverse, then drastic steps may need to be taken if the company is to survive.

Responses to changes in corporate health. It is clear from what has been said before that management policies are not only constrained by a company's liquidity and profitability, they also affect both of those variables.

Expenditure on physical loss control or the purchase of insurance, like any other form of expenditure, reduces a company's liquidity in the short-run. In the longer-run it may have a beneficial effect either by reducing the cash outflows or the loss of sales receipts due to the occurrence of loss producing events, or through claims recoveries from insurers.

The effect on profitability is more complex. Normally, as noted above, the purchase of insurance will reduce annual expected profit. The insurer will aim to charge an 
annual premium $(P)$ related to the loss expectancy transferred plus a contingency, expenses and profit loading, as follows :

$$
P=\left(q \times \bar{c}_{l}\right)(1+i)^{-t}+L
$$

where $q$ represents the estimation of the probability of the event occurring in any one year ;

$\bar{c}_{t}$ represents the estimated average claims cost $(\mathcal{c})$ and the average claims occurrence and settlement delays $(t)$;

$i$ is the discount rate allowed by the insurer in recognition of the investment earnings he will obtain on funds;

$L$ is the premium loading.

If the firm chose not to insure, its expected risk retention cost $(R)$ would be :

$$
R=\left(q \times \bar{c}_{t}\right)(1+r)^{-t}
$$

where $r$ represents the rate of return it could obtain by investing the funds.

Therefore, ignoring any differences in administration costs, the purchase of insurance would increase the firm's annual expected profits only if the following condition were met :

$$
\left(q \times \bar{c}_{t}\right)\left[\frac{1}{(1+r)^{t}}-\frac{1}{(1+i)^{l}}\right]>L \quad, \text { where } i>r .
$$

In reality it is highly improbable that $i$ would sufficiently exceed $r$ as to more than offset the premium loading.

The effect on annual actual profit of buying insurance is uncertain due to the stochastic nature of insured losses. Premiums paid will always be a charge on the profits, but in years when claims recoveries exceed premiums paid the company will enjoy a larger profit (or smaller loss) than if it were uninsured.

Physical loss control projects that are forecast to yield financial benefits greater than the financial costs should increase expected profit. The timing of that benefit will depend, however, on the nature of the project and the accounting conventions employed (for example, whether all or part of the expenditure is capitalised). The impact on actual annual profits will additionally depend on whether the benefit takes the form of guaranteed premium reductions or savings arising from the occurrence of fewer and/or less costly loss producing events.

Clearly, therefore, risk handling decisions are not amenable to a set of simple decision rules. Consideration must be given not only to long-run expected benefits but also to possible effects on short-term liquidity, accounted profit and the state of the balance sheet at the end of each year. Trade-offs between profitability and security are unavoidable.

A company in a state of " normal" financial health is bound to subject all expenditure to careful financial scrutiny. However, the levels of earnings and dividend 
distribution required to keep shareholders satisfied will be related directly to the degree of risk they are asked to bear, so that management will have some freedom of action in relation to risk handling. Therefore a company that is prepared to incur the costs and accept the associated risks of, say, launching a new product in order to increase profits in the long-run, might also be prepared to accept a higher degree of variability in actual pure risk costs in return for an immediate or eventual reduction in expected risk costs. So the risk manager might be encouraged to explore the savings possible from partial insurance arrangements and physical loss control projects. It is highly unlikely, however, that in order to secure modest savings in expected risk costs top management would willingly expose the company to losses of a size that could imperil its survival as an independent organization, particularly if it was also subjects to substantial business risks. So in preparing his insurance programme, the risk manager probably would follow the conventional wisdom of concentrating on loss severities rather than loss frequencies, and so buy insurance against catastrophe type risks even though their probability of occurrence was very small.

Any improvements in profit potential taking a company into an "excellent" state of financial health, eases the financial constraints. It can then afford to :

- indulge in physical loss control projects that for humanitarian or other reasons may be deemed desirable but may not be justifiable on strictly economic grounds. For example, the estimated net benefits may be deemed too uncertain or fail to meet a target rate of return and/or payback period;

- retain more of its risks : high liquidity and fund raising capacity could be used to provide the financing support for, perhaps, carrying higher deductibles or even wholly cancelling some forms of insurance;

- set-aside funds, possibly from retained profits, to support a programme of selfinsurance by establishing an internal contingency fund or a captive insurance company.

None of these things may happen for various reasons. Preference may be given to other projects competing for available funds, and tax rates and rules may significantly affect net of tax returns. Nevertheless the company will be in a position to assume more risk and to pursue non-profit objectives.

Any deterioration in liquidity or profit potential, taking the company into a "subnormal" state of health, must produce the opposite reaction. The need to maintain liquidity becomes paramount. Therefore one reaction may be to reverse the risk retention process and buy more insurance, as suggested in the introduction to this paper. However, that could have an adverse initial effect on liquidity, unless arrangements could be made to spread premium payments instead of paying in full at inception. That is precisely what has happened in Britain, where insurance companies seeking to retain business not only are competing vigorously on price but also on premium instalment plans. Another reaction might be to release assets set aside for internal contingency (self-insurance) funds to boost working capital or finance essential projects. than :

As for physical loss control, shortage of funds may preclude any projects other 
- essential safety, etc. measures where non-compliance with regulations could possibly involve the closure of a plant; and

- any measure requiring no significant additional expenditure, such as changes in routines and procedures.

Even if some funds could be made available, only projects with short pay-back periods which would quickly produce positive cash-flow benefits would be likely to be considered. As financial conditions worsen, so planning horizons inevitably become shorter.

A company that finds itself in the "terminal" stage will be forced to take desperate measures in order to survive. The first priority must be to improve cash flow so that any expenditure which is not directly and very rapidly contributing to the generation of income, or preventing even larger cash outflows, must be questionned: there is no reason why expenditure on the control of risks should be exempted. It is one of life's paradoxes that those who can least afford to suffer a loss can also least afford to buy security.

Therefore current expenditure on physical loss control may be reviewed : there is much evidence, for example, of British companies cutting back on the maintenance of buildings, vehicles and plant. Expenditure on new projects becomes even more unlikely to receive approval.

Expenditure on non-compulsory insurances likewise could be a candidate for cancellation. Given the need to avoid any unexpected demands on liquidity, loss frequencies now assume far greater importance. Thus a case can be made for retaining the insurance on risks with relatively high loss frequencies though relatively modest loss severities which nevertheless could ruin the company. Any cut in premium rates or the option to pay the premium by instalments strengthens that case. On the other hand it would be a reasonable decision for a company struggling for survival to strengthen its liquidity and so its short-run chances of survival by not paying the premium to insure against a catastrophe type risk with a, say, 1 chance in 100 years of a loss occurring.

\section{Conclusion}

Risk management is but one of the many management functions undertaken in a company, and the authority and responsibilities vested in risk managers, and the systems of directives and controls to which they are subject designed to achieve the attainment of chosen corporate objectives, vary considerably between companies. There are, however, three factors which all decision-takers, including those involved in the management of pure risks, need to take into account; they are profitability, liquidity and borrowing capacity.

The aim of this paper has been to show how those factors are both affected by and may act as constraints on the way risks are controlled. In particular an attempt has been made to show how they explain the changes that have occurred in recent years in the management of pure risks, especially in regards to insurance/risk retention and physical loss control programmes. It has been shown how the deterioration of a company's financial condition can restrict its freedom of action and even lead to a reversal of risk handling policies. 


\section{REFERENCES}

BAUMOL, W. H. [1959] : Business Behaviour, Value and Growth, Mac Millan, London.

CARTER, R. L. [1974] : Handbook of Risk Management, Kluwer, London.

CYERT, R. M., and MARCH, J. G. [1963] : A Behavioural Theory of the Firm, Prenctice Hall, Englewood Cliffs (New Jersey).

DOHERTY, N. [1976] : Insurance Pricing and Loss Prevention, Saxon House, Farnborough (Hants.).

DRUCKER, P.F. [1974] : Management, Heinemann, London.

DRUCKER, P. F. [1980] : Managing in Turbulent Times, Heinemann, London.

GASELEE, J. [1981] : “Cover in the recession", Post Magazine and Insurance Monitor, 142 (20 August 1981), 2106-2107.

GREENE, M. R., and SERBEIN, O.N. [1978] : Risk Management : Text and Cases, Reston Publishing Co.

HAWKINS, C. J. [1973] : Theory of the Firm, MacMillan, London.

LEE, G. A. [1981] : Modern Financial Accounting, Nelson, London.

MEHR, R. I., and FORBES, S.W. [1973]: "The risk management decision in the total business setting ", Journal of Risk and Insurance, 40 (September 1973), 389-401.

SAMUELS, J.M., and WILKES, F.M. [1980] : Management of Company Finance, Nelson, London.

WILLIAMS, C. A. [1966]: "Attitudes towards speculative risk as an indicator of attitudes towards pure risk", Journal of Risk and Insurance, 33 (December 1966), 577-586.

WILliaMSON, O.E. [1970]: Corporate Control and Business Behaviour, Prenctice Hall, Englewood Cliffs (New Jersey). 